University of Nebraska - Lincoln

DigitalCommons@University of Nebraska - Lincoln

Nutrition and Health Sciences -- Faculty

Publications

Nutrition and Health Sciences, Department of

4-3-2015

Food Resource Management Education With SNAP Participation

Improves Food Security

Lucia Kaiser

Virginia Chaidez

Susan Algert

Marcel Horowitz

Anna Martin

See next page for additional authors

Follow this and additional works at: https://digitalcommons.unl.edu/nutritionfacpub

Part of the Human and Clinical Nutrition Commons, Molecular, Genetic, and Biochemical Nutrition Commons, and the Other Nutrition Commons

This Article is brought to you for free and open access by the Nutrition and Health Sciences, Department of at DigitalCommons@University of Nebraska - Lincoln. It has been accepted for inclusion in Nutrition and Health Sciences -- Faculty Publications by an authorized administrator of DigitalCommons@University of Nebraska Lincoln. 


\section{Authors}

Lucia Kaiser, Virginia Chaidez, Susan Algert, Marcel Horowitz, Anna Martin, Concepcion Mendoza, Marisa Neelon, and David C. Ginsburg 


\title{
Food Resource Management Education With SNAP Participation Improves Food Security
}

\author{
Lucia Kaiser, $\mathrm{PhD}, \mathrm{RD},{ }^{1,2}$ Virginia Chaidez, $\mathrm{PhD}, \mathrm{RD},{ }^{3,4}$ \\ Susan Algert, PhD, RD, ${ }^{2,4}$ Marcel Horowitz, MS, MCHES, ${ }^{2,4}$ \\ Anna Martin, $\mathrm{MA}^{2,4}$ Concepcion Mendoza, $\mathrm{PhD},{ }^{2,4}$ \\ Marisa Neelon, MS, RD, ${ }^{2,4}$ and David C. Ginsburg, $\mathrm{MPH}^{4}$
}

1 Nutrition Department, University of California at Davis, Davis, CA

2 University of California Agriculture and Natural Resources, Cooperative

Extension, University of California, Davis, CA

3 Nutrition and Health Sciences Department, University of Nebraska-Lincoln, Lincoln, NE

4 University of California CalFresh (SNAP-Ed) Nutrition Education Program, Davis, CA

Correspondence - Virginia Chaidez, PhD, RD, Nutrition and Health Sciences Department, University of Nebraska-Lincoln, 104A Leverton Hall, Lincoln, NE 68583;

Phone: (402) 472-7647; Email: vchaidez2@unl.edu

\begin{abstract}
Objective: To determine the influence of Supplemental Nutrition Assistance Program (SNAP) and participant demographics on nutrition education outcomes.

Methods: At program enrollment (pre) and 1 month later (post), a statewide convenience sample of adults, who participated in the Plan, Shop, Save, and Cook

Published in Journal of Nutrition Education and Behavior, Volume 47, Number 4 (2015), pp 374-378

DOI: http://dx.doi.org/10.1016/j.jneb.2015.01.012

Copyright (C)2015 Society for Nutrition Education and Behavior. Published by Elsevier, Inc. Used by permission.

Submitted January 31, 2015; published April 3, 2015.
\end{abstract}


program, completed a 7-item questionnaire to evaluate change in resource management skills (RMS) and running out of food before the end of the month.

Results: Percent of participants $(n=3,744)$ who reported behavioral improvements in RMS ranged from $38.8 \%$ in comparing prices to $54 \%$ in reading labels. Female gender and Hispanic ethnicity were positively related to pre-post RMS change ( $\mathrm{P}$ $=.001$ ). Participants who received SNAP food assistance and made greater prepost improvement in RMS reported the greatest decrease in running out of food $(\mathrm{P}=.001)$.

Conclusions and Implications: Both food assistance and education on nutrition and resource management are needed to reduce food insecurity in SNAP-eligible audiences.

Keywords: food resource management, nutrition education, food insecurity, Supplemental Nutrition Assistance Program, SNAP-Ed

\section{Introduction}

In $2012,14.5 \%$ of US households were food insecure, meaning they lacked access to enough food for an active, healthy life for all household members. ${ }^{1}$ About $25 \%$ of Hispanic and African American households were food insecure, compared with $11 \%$ of white households. Prevalence of food insecurity also was higher than the US figure (14.5\%) among households that had income less than the federal poverty level (40\%), had female heads and children (35.4\%), resided in the principal cities of metropolitan areas (16.9\%), or resided in the southern US (16\%).

Food insecurity in children, adolescents, and adults has been associated with negative outcomes such as inadequate nutrient intakes, poor mental and physical health, substandard economic performance, increased risk of chronic disease, poor psychological and cognitive function, and obesity. ${ }^{2-4}$ Factors contributing to food insecurity in the US include poverty, unemployment, and low education ${ }^{2,3}$; high housing, transportation, utility, and medical expenses; ${ }^{3}$ mental health problems $\mathrm{s}^{3,4}$; and substance abuse. ${ }^{3}$ Ameliorating food insecurity requires adequate funding and use of food assistance and innovative programs to promote individual and household economic self-sufficiency through community based strategies and nutrition education. ${ }^{3}$ Food security is a human rights issue, hence policy decisions can be made to improve the food security, health, and well-being among the most vulnerable population groups. ${ }^{5}$ 
Increasing Supplemental Nutrition Assistance Program (SNAP) monetary benefits may reduce household stress, ${ }^{6}$ improve food security, ${ }^{7,8}$ and make it easier for families to purchase healthy foods. ${ }^{9}$ Among lowincome families ( $\mathrm{n}=501)$, greater severity of food insecurity increased the odds of experiencing rent and bill hardships, giving up services, pawning possessions, and limiting purchases of milk, vegetables, and fruit. ${ }^{9}$ A North Carolina study $(\mathrm{n}=202)$ revealed that body mass index was greater in households receiving $<\$ 150$ in SNAP food assistance per member, compared with those who received $\geq \$ 150 .{ }^{10}$ Food insecurity and obesity may coexist because the least expensive foods are often low in nutrients and energy dense. ${ }^{11-13}$ However, SNAP alone without nutrition education may not be sufficient to help participants adhere to a healthy diet. ${ }^{14}$

To counter the dual problem of food insecurity and obesity, nutrition education, including SNAP Nutrition Education (SNAP-Ed), can help participants maximize use of food dollars to buy healthy foods by teaching individual and household economic self-sufficiency. ${ }^{3}$ Low-income households with greater financial management skills are less likely to be food insecure ${ }^{15} \mathrm{~A}$ multi-state study has reported the effectiveness of nutrition education in improving food resource management skills in low-income audiences. ${ }^{16}$ An effective SNAP-Ed program intervention teaches household resource management skills, and when coupled with SNAP food assistance, can help reduce food insecurity and increase purchases of healthful foods.

To respond to this need, cooperative extension nutrition advisors created the Plan, Shop, Save, and Cook (PSSC) class series, adapted from Eating Smart Being Active, which is based on the Social Cognitive and Adult Learning Theories (http://www.ext.colostate.edu/esba/). In the 4-class PSSC series, paraprofessionals teach participants how to plan meals, read food labels to select healthy foods, compare prices to save money, and implement time-saving cooking tips. Each 1-hour class, offered to small groups of adults in a community setting, includes skillbuilding activities such as creating a menu and comparing it with current dietary recommendations. Participants taste low-cost healthy foods and receive recipes to try at home. The University of California at Davis SNAP-Ed program, known as UC CalFresh, began delivering PSSC statewide in 2011. Using statewide data from 2011 to 2013, this article determines the influence of SNAP participation and demographic 
characteristics on PSSC nutrition education outcomes, defined as an increase in using food resource management skills and decrease in running out of food (ROF) before the end of the month (an indicator of food security).

\section{Materials and methods}

The University of California at Davis Institutional Review Board approved the Human Subjects Protocol for this study. The Human Subjects Protocol approves materials and procedures for program evaluation and does not require written or verbal consent of participants. In federal fiscal year 2010, the UC CalFresh State office mandated all county programs to include adults in their nutrition education efforts. All cooperative extension paraprofessionals participated in online webinar training on recruitment, direct delivery methods, and evaluation of the PSSC program. From October, 2011 through September, 2013, paraprofessionals in 15 California counties partnered with various communitybased organizations to recruit SNAP or SNAP-eligible adult participants. The PSSC classes were delivered on-site to small groups averaging 15 adults over 1-month periods. Participants completed the pre and postevaluation questionnaire before the first lesson and 1 month later at the end of lesson 4. Only those who completed both pre- and postquestionnaires are included in the sample. At baseline only, they also completed a 5-item demographic form that asked about age, gender, race, ethnicity, and SNAP participation. The pre-post tool included 6 resource management items and 1 food security item with a 5-option Likert-type response: 0 = never; 1 = seldom; 2 = sometimes; 3 = most of the time; and $4=$ always. These items were chosen because previous studies have reported significant associations between several of them and diet quality. ${ }^{17}$ Moreover, they are used nationally to evaluate similar nutrition education classes offered through the Expanded Food and Nutrition Education Program. ${ }^{18}$

A food resource management score (RMS) was created by summing the frequency ( $0=$ never to $4=$ always $)$ of planning meals, using a list, comparing prices, reading labels, thinking about healthy choices, and eating varied meals (range, $0-30$; Cronbach $\alpha=$.77). Pre-post change in score for ROF ranged from -4 to +4 based on the item, How often do 
you run out of food before the end of the month? Because other random events in participants' lives beyond the PSSC program, such as the addition of a new family member or sudden job loss, can influence food security, the pre-post ROF change could be positive or negative. A negative sign in ROF may indicate a potential improvement in food security. Definitions for race included non-Hispanic white (1) or other race (0). Definitions for ethnicity included Hispanic/Latino (1) or non- Hispanic/ Latino (0). Age was < 60 years (0) or $\geq 60$ years (1).

The researchers analyzed data using SAS for Windows (version 9.30, SAS Institute, Cary NC, 2010). Frequencies were calculated for the 5 demographic variables. Chi-square test was used to examine differences in demographic characteristics between 2011-2012 and 2012-2013. Based on the Anderson- Darling test for normality, distributions of the behavioral items were not normal. Therefore, the signed rank test was used to examine pre- post change in the behavioral items. Pearson correlation coefficients were calculated to examine bivariate relationships. Multivariate linear regression (PROC GLM) was used to examine the influence of SNAP, age, race, ethnicity, and gender on program outcomes. The RMS analysis explored whether interactions existed between SNAP participation and the demographic characteristics. The analysis also examined potential interactions between pre-post change in RMS and SNAP in reducing ROF. $P>.05$ was considered not significant.

\section{Results}

Few demographic differences were observed between fiscal year 2011- $2012(n=1,371)$ and fiscal year 2012-2013 ( $n=2,371)$, although the program reached more participants in its second year. Most PSSC participants in both years were aged 18-59 years (89\%), female (74\%), and of Hispanic/Latino ethnicity (65\%). More than half (63\% in 2011-2012 and 54\% in 2012-2013; $P<.001$; $58 \%$ total sample) were currently enrolled in the SNAP program.

Table 1 lists the percentage of participants who reported improvement (pre-post changes) in resource management behaviors. The greatest behavior change was observed in using the Nutrition Facts label (54\% in 2012 and $52.2 \%$ in 2013 reported more frequent use; difference between 2012 and 2013, not significant). Fewer participants 
Table 1. Pretest and Posttest Resource Management Behaviors in Plan, Shop, Save, and Cook Participants

\begin{tabular}{|c|c|c|c|c|c|c|c|c|c|c|c|c|}
\hline \multirow[b]{2}{*}{ Items (\%) } & \multicolumn{2}{|c|}{$\begin{array}{l}\text { Plan } \\
\text { Meals }\end{array}$} & \multicolumn{2}{|c|}{$\begin{array}{c}\text { Compare } \\
\text { Prices }\end{array}$} & \multicolumn{2}{|c|}{$\begin{array}{c}\text { Shop } \\
\text { With List }\end{array}$} & \multicolumn{2}{|c|}{$\begin{array}{l}\text { Think About } \\
\text { Healthy Choices }\end{array}$} & \multicolumn{2}{|c|}{$\begin{array}{c}\text { Use Nutrition } \\
\text { Facts }\end{array}$} & \multicolumn{2}{|c|}{$\begin{array}{l}\text { Varied } \\
\text { Meals }\end{array}$} \\
\hline & FY12 & FY13 & FY12 & FY13 & FY12 & FY13 & FY12 & FY13 & FY12 & FY13 & FY12 & FY13 \\
\hline Pretest: always or most & 43.9 & 47.5 & 64.0 & 61.7 & 43.4 & 45.2 & 60.1 & 61.2 & 29.3 & 29.6 & 67.9 & 64.2 \\
\hline Posttest: always or most & 69.4 & 66.5 & 76.3 & 76.9 & 66.0 & 63.7 & 77.6 & 75.3 & 58.3 & 55.3 & 81.3 & 79.7 \\
\hline Participants who improved & 45.6 & 41.4 & 35.6 & 38.8 & 43.8 & 42.9 & 40.2 & 39.3 & 54.0 & 52.2 & 37.6 & 39.4 \\
\hline
\end{tabular}

FY indicates financial year.

Notes: $\mathrm{n}=1$ 1,373, FY12; $\mathrm{n}=2$,371, FY13. Signed-rank test was used for pre-post responses, based on a 5-point Likert scale, for each item (both separately and years combined); $\mathrm{P}<.001$.

reported behavior changes in comparing prices and eating varied meals more often. More than one third reported a reduction in the frequency of ROF before the end of the month (33.4\% in 2012 and $38.3 \%$ in 2013; $P<.001)$.

Greater use of resource management skills, measured by pre-post evaluation, was significantly related to reduction in ROF. The correlations were stronger in SNAP participants $(r=-.24 ; P=.001)$ than in SNAP eligible participants $(r=-.09 ; P=.01)$. To account for the effects of demographic variables that might be associated with SNAP participation, multivariate regression examined the influence of SNAP on improvement in RMS (Table 2). No interactive effects of SNAP with age, gender, race, or ethnicity were observed. Hispanic/ Latino ethnicity and female gender were positively related to greater improvement in RMS after participation in the PSSC program $(P<.001)$. Adjusted for age, gender, ethnicity, and race, SNAP participation was not significantly related to change in RMS (Table 2). Participants who received SNAP benefits and made more pre- post improvement in RMS reported the greatest decrease in ROF (mean change, -0.52 in SNAP vs -0.23 in non-SNAP participants; $P=.001$ ).

\section{Discussion}

A short (1-month) follow-up period after delivery of the PSSC program revealed that greater improvement in resource management skills was associated with a reduction in food insecurity, as measured by ROF before the end of the month. However, the association was significant only in participants who received SNAP benefits. 
Table 2. Multivariate Linear Regression: Post-Pre Change in Resource Management Score and Running Out of Food ( $\mathrm{n}=3,744)$

\begin{tabular}{|c|c|c|c|c|}
\hline \multirow[t]{2}{*}{ Predictor Variable } & \multicolumn{2}{|c|}{$\begin{array}{l}\text { Model 1: Change in RMS } \\
\quad \text { Parameter }\end{array}$} & \multicolumn{2}{|c|}{$\begin{array}{l}\text { Model 2: Change in ROF } \\
\text { Parameter }\end{array}$} \\
\hline & Estimate (SE) & $P$ & Estimate (SE) & $P$ \\
\hline Intercept & $+10.20(0.30)$ & .001 & +1.03 (0.09) & .001 \\
\hline Year (1 = 2011-2012; 2 = 2012-2013) & $-0.06(0.11)$ & .61 & $-0.13(0.04)$ & .001 \\
\hline Baseline RMS ${ }^{a}$ & $-0.46(0.01)$ & .001 & - & - \\
\hline Baseline ROF ${ }^{b}$ & $+0.004(0.04)$ & .93 & $-0.52(0.01)$ & .001 \\
\hline Age, y $(0 \leq 60 ; 1 \geq 60)$ & $-0.27(0.18)$ & .14 & $-0.10(0.06)$ & .09 \\
\hline Gender $(0=$ male; 1 = female $)$ & $+0.40(0.12)$ & .001 & $+0.02(0.39)$ & .70 \\
\hline Latino ( 0 = non-Latino; 1 = Latino) & $+0.90(0.17)$ & .001 & $+0.002(0.06)$ & .97 \\
\hline Non-Latino white $(0=$ no; $1=$ yes $)$ & $+0.005(0.19)$ & .98 & $-0.04(0.06)$ & .51 \\
\hline SNAP $(0=$ non-participant; 1 = participant $)$ & $-0.19(0.17)$ & .07 & - & - \\
\hline Interaction (SNAP_ post-pre RMS) & - & - & $-0.04(0.009)$ & .001 \\
\hline $\mathrm{F}$ & 235.6 & .001 & 173.1 & .001 \\
\hline Multivariate coefficient & 0.33 & 0.29 & & \\
\hline
\end{tabular}

RMS indicates Resource Management Score; ROF, running out of food; SNAP, Supplemental Nutrition Assistance Program.

a. Resource Management Score is the sum of planning meals, shopping with a list, comparing prices, reading labels, thinking about healthy food choices, and eating a variety of foods. Responses are: 0 = never; 1 = seldom; 2 = sometimes; 3 = most of the time; or $4=$ always. A positive sign indicates increase in resource management skills;

b. Running out of food is measured by: How often do you run out of food before the end of the month? 0 = never; 1 = seldom; 2 = sometimes; 3 = most of the time; or $4=$ always. A negative sign means reduction in food insecurity.

Previous research in low-income audiences has shown that shortterm interventions can change attitudes and increase financial savvy related to purchasing healthy foods. ${ }^{16-19}$ The finding that Latino ethnicity was associated with greater change in resource management skills may be because of their relatively high levels of food insecurity. ${ }^{1}$ which could act as a motivator to stretch food dollars. Another reason may be that recently arrived Latino immigrants are less familiar with the US food system, compared with US-born Latinos, and may lack knowledge and skills to choose food products offered in a large supermarket. A study conducted in California reported that Latinas with low acculturation levels use smaller grocery stores more often than larger supermarkets. ${ }^{20}$ Thus, the likelihood of increasing knowledge and skills through education may be higher in Spanish-speaking, low-income Latino adults than in the general US population. 
In this study, females reported greater behavior change than male participants. One possibility is that households headed by single mothers are particularly vulnerable to food insecurity ${ }^{1}$ and thus, women who are able to attend a 4-session class may be more motivated and ready to make changes.

It can be difficult to determine the effect of SNAP on reducing food insecurity because of the self-selection bias of needier households into the program. Nonetheless, national data comparing short-term food security outcomes among SNAP participants and those leaving the program suggest that SNAP has an ameliorative effect of $20 \%$ to $50 \%$ on very low food security. ${ }^{8}$ A small longitudinal study in Massachusetts $(n=107)$ did not find a significant reduction in food insecurity or improvement in diet quality over a 3-month period among SNAP recipients, compared with program applicants. ${ }^{21}$ However, neither of these studies examined the contribution of changes in resource management skills, tied to nutrition education, on food insecurity in SNAP and non-SNAP populations. A randomized controlled intervention evaluating the Expanded Food and Nutrition Education Program reported that food resource management skills improved as a result of nutrition education and, more important, continued to improve with completion of the classes. ${ }^{18} \mathrm{How}$ ever, food insecurity, as measured by ROF, did not continue to improve. The findings from this study and previous research ${ }^{18,21}$ suggest that neither nutrition education nor food assistance alone is sufficient to affect food insecurity. The current study suggests that nutrition education that promotes resource management behaviors, in combination with SNAP benefits, can help families make their food last until the next paycheck and SNAP benefits arrive.

Limitations of this study include lack of a control or comparison group that did not receive the PSSC program, a short follow-up period (1 month), only 1 item used as an indicator of food insecurity, lack of data on participants who were lost to follow-up, lack of data on amounts of SNAP benefits participants received, and limited demographic data on participants. Because SNAP and SNAP-eligible populations are hard to reach and sometimes transitory, long-term follow-up studies may not yield a representative sample without investing significant effort and funds. However, the strength of the study is a large, statewide sample on a SNAP-Ed adult population, in a real-world setting, that is demographically similar over 2 consecutive years. Although only a few demographic and outcome variables were collected to reduce participant burden, the 
study is able to report on the same national behavior change indicators used in the Expanded Food and Nutrition Education Program. This ultimately will enable comparison with findings from studies in other US Department of Agriculture programs and in other states. ${ }^{16}$

\section{Conclusions and implications}

The goal of SNAP-Ed is to improve the likelihood that persons eligible for SNAP make healthy food choices, within limited budgets, consistent with the Dietary Guidelines for Americans. Targeted nutrition education programs such as PSSC, linked with food assistance benefits and designed to support comprehensive, community-based strategies, can make healthier food choices easier and improve food security, even within limited budgets and under stressful life situations. Further studies should examine the long term impact of resource management education, delivered through PSSC and other SNAP-Ed programs, on food insecurity and other outcomes in low-income adults. A key area to explore is whether resource management education can help lowincome women living in high-stress situations improve food security and counteract the purchase of inexpensive energy-dense foods.

Acknowledgments - This study was funded by US Department of Agriculture SNAPEd; US Department of Agriculture/National Institute of Food and Agriculture Project CA-D-NTR-2117-H; and University of California Agriculture and Natural Resources.

\section{References}

1. Coleman-Jensen A, Nord M, Singh A. Household Food Security in the United States in 2012. Alexandria, VA: US Department of Agriculture, Economic Research Service; 2013.

2. Coleman-JensenA, McFall W, Nord M. Food insecurity in households with children: prevalence, severity, and household characteristics, 2010-11. http://www.ers. usda.gov/media/1120651/eib-113.pdf. Accessed November 25, 2014.

3. Holben D. Position of the American Dietetic Association: Food insecurity in the United States. J Am Diet Assoc. 2010;110:1368-1377.

4. Kaiser L, Baumrind N, Dumbauld S. Who is food-insecure in California? Findings from the California Women's Health Survey, 2004. Public Health Nutr. 2007;10:574-581. 
5. Chilton M, Rose D. A rights-based approach to food insecurity in the United States. Am J Public Health. 2009;99:1203-1211.

6. Casey P, Goolsby S, Berkowitz C, et al. Maternal depression, changing public assistance, food security, and child health status. Pediatrics. 2004;113: 298-304.

7. Mabli J, Worthington J. Supplemental Nutrition Assistance Program participation and child food security. Pediatrics. 2014;133:610-619.

8. Nord M. How much does the Supplemental Nutrition Assistance Program alleviate food insecurity? Evidence from recent programme leavers. Public Health Nutr. 2012;15:811-817.

9. Loopstra R, Tarasuk V. What does increasing severity of food insecurity indicate for food insecure families? Relationships between severity of food insecurity and indicators of material hardship and constrained food purchasing. J Hunger Environ Nutr. 2013;8: 337-349.

10. Jilcott SB, Wall-Bassett ED, Burke SC, Moore JB. Associations between food insecurity, supplemental nutrition assistance program (SNAP) benefits, and body mass index among adult females. J Am Diet Assoc. 2011;111:1741-1745.

11. Drewnowski A. The economics of food choice behavior: why poverty and obesity are linked. Nestle Nutr Inst Workshop Ser. 2012;73:95-112.

12. Townsend MS, Aaron GJ, Monsivais P, Keim NL, Drewnowski A. Less-energydense diets of low-income women in California are associated with higher energy-adjusted diet costs. Am J Clin Nutr. 2009;89:1220-1226.

13. Nackers LM, Appelhans BM. Food insecurity is linked to a food environment promoting obesity in households with children. J Nutr Educ Behav. 2013; 45:780-784.

14. Hilmers A, Chen TA, Dave JM, Thompson D, Cullen KW, et al. Supplemental Nutrition Assistance Program participation did not help low income Hispanic women in Texas meet the dietary guidelines. Prev Med. 2014;62:44-48.

15. Gundersen CG, Garasky SB. Financial management skills are associated with food insecurity in a sample of households with children in the United States. J Nutr. 2012;142:1865-1870.

16. AuldG, Baker S, Conway L, Dollahite J, Lambea MC, McGirr K.Outcome effectiveness of the widely adopted EFNEP curriculum Eating Smart Being Active. J Nutr Educ Behav. 2015;47:19-27.

17. Hersey J, Anliker J, Miller C, et al. Food shopping practices are associated with dietary quality in low-income households. J Nutr Educ. 2001;33(Suppl 1):S16-S26.

18. Dollahite JS, Pijai EI, Scott-Pierce M, Parker C, Trochim W. A randomized controlled trial of a community-based nutrition education program for low income parents. J Nutr Educ Behav. 2014;46:102-109.

19. Rustad C, Smith C. A short-term intervention improves nutrition attitudes in lowincome women through nutrition education relating to financial savvy. J Hunger Environ Nutr. 2012;7:205-223. 
20. Ayala GX, Mueller K, Lopez- Madurga E, Campbell NR, Elder JP. Restaurant and food shopping selections among Latino women in Southern California. J Am Diet Assoc. 2005; 105:38-45.

21. Leung CW, Cluggish S, Villamor E, Catalano PJ, Willett WC, Rimm EB. Few changes in food security and dietary intake from short-term participation in the Supplemental Nutrition Assistance Program among low-income Massachusetts adults. J Nutr Educ Behav. 2014;46:68-74. 